\title{
FREQUENCY AND CORRELATES OF MYOPATHY IN PATIENTS WITH DIABETES TAKING ATORVASTATIN
}

\author{
Kamil Rehman Butt, Andaleeb Khan, Ali Muhammad, Jawad Khan, Ejaz Ali*, Usama Bin Zubair** \\ Pak Emirates Military Hospital/National University of Medical Sciences (NUMS) Rawalpindi Pakistan, *Combined Military Hospital Quetta/National University \\ of Medical Sciences (NUMS) Pakistan, **Pakistan Institute of Medical Sciences, Islamabad Pakistan
}

\section{ABSTRACT}

Objective: To determine the myopathy in patients with diabetes taking atorvastatin and look for the factors correlated with the presence of myopathy among these patients.

Study Design: Cross sectional analytical study.

Place and Duration of Study: Department of Medicine, Pak Emirates Military Hospital Rawalpindi from, Jul to Dec 2018.

Methodology: A total of 166 patients of both genders with type 2 diabetes mellitus taking atorvastatin for at least three to twelve months were included. Blood samples were drawn and Creatinine kinase (CK) levels were determined by automated analysis by colorimetry. Myopathy was taken as muscle symptoms associated with elevations in Creatinine Kinase at least 10 times the upper limit of normal.

Results: Mean age of patients was $51.530 \pm 5.70$ years with age range from 40-70 years with. Mean duration of diabetes was $6.174 \pm 2.27$ years, mean duration of taking atorvastatin $7.186 \pm 2.17$ months and mean creatinine kinase levels were $1760.325 \pm$ $5111.71 \mathrm{IU} / \mathrm{L}$. Males were $68.7 \%$ as compare to females $31.3 \%$. Myopathy was seen in $8.4 \%$ patients. Long duration of Diabetes Mellitus and atorvastatin use was statistically significantly related with the presence of myopathy.

Conclusion: Myopathy was found in a significant number of patients taking atorvastatin. High risk population in our study emerged out to be patients with long duration of Diabetes Mellitus and long use of atorvastatin.

Keywords: Atorvastatin, Diabetes mellitus, Myopathy.

This is an Open Access article distributed under the terms of the Creative Commons Attribution License (http://creativecommons.org/licenses/by/4.0), which permits unrestricted use, distribution, and reproduction in any medium, provided the original work is properly cited.

\section{INTRODUCTION}

Treatment of hypercholesterolemia and the management of patients with increased cardiovascular disease (CVD) risk have been revolutionized by the use of Hydroxy-methyl-glutaryl-coenzyme-A (HMGCoA) reductase inhibitors or statins. These drugs are usually well tolerated but still associated with certain adverse effects associated with various systems of the human body. These effects have been usually mild and resolve with dose reduction or time adjustment ${ }^{1,2} .10 \%, 1-25 \%$ patients who are onstatins show adverse effects related to the musculoskeletal system ${ }^{2}$. More than 60 percent patients on these medications report the side effects or ultimately stop the drug due to these effcts ${ }^{2}$. Stopping the statins is surely counter therapeutic and linked with high mortality and morbidity among the patients suffering from cardiovascular disorders ${ }^{3}$.

Statins cause a number of musculoskeletal problems which have a full spectrum ranging from mild myalgias to severe form of rhabdomyolysis. These usually occur without even rise in the creatinine kinase enzyme. Sometimes the serious complication like rhabdomyolysis may have a prodrome of mild form

Correspondence: Dr Kamil Rehman Butt, Department of Medicine, Pak Emirates Military Hospital, Rawalpindi Pakistan

Received: 22 May 2019; revised received: 23 Dec 2019; accepted: 27 Dec 2019 and then a full blown clinical picture of rhabdomyolysis can be seen ${ }^{4}$. Still there is a consensus among the various medical bodies to use the rise in creatinine kinase as an entity to differentiate various form of statin related muscle problems ${ }^{5}$. Sometimes these classifications and definitions without various cutoff re more useful for research purpose than clinical utility. The ACC / AHA and CWG, ${ }^{6}$ defined rhabdomyolysis as a $C K>10_{-}$the upper limit of normal (ULN), which is approximately 2,000 U/1. In clinical practice this is not the only factor which should be taken into account as hydration status and other patient related factors may be responsible for determining the severity of rhabdomyolysis so mostly it is the clinical picture not the raised enzyme which should be considered. The NLA's use of CK values to stage myonecrosis ${ }^{7}$, is useful for case definition, but CK elevations do not necessarily indicate myonecrosis and may only represent sarcolemmal injury and CK leak. The NLA requires muscle weakness to diagnose myositis ${ }^{7}$, and weakness is frequently reported by patients, but rarely objectively documented, even in those reporting statin myalgia ${ }^{8}$. where the clinical diagnosis of SAMS depends primarily on subjective clinical assessment. Therefore clinicians should keep the level of suspicion high for myopathy in all the patients taking the statins with or without rise in CK levels. 
Manoj et al in their analysis has concluded that prevalence of myopathy was $7.5 \%$ in diabetic patients taking atorvastatin ${ }^{9}$. Considering the high prevalence of diabetes and concomitant use of statins in clinical practice, limited literature on the said subject and the frequent complaints of unexplained muscle aches, tenderness and weakness in patients taking statins can significantly pose problems in terms of compliance and understanding the magnitude of problem so objective of this study was to estimate the frequency of myopathy in patients with diabetes taking atorvastatin in the outpatient settings of a tertiary care hospital in Pakistan.

\section{METHODOLOGY}

This cross-sectional analytical study was conducted at department of Medicine, Pak Emirates Military Hospital Rawalpindi, from July to December 2018. WHO Sample Size Calculator was the tool used to calculate the size of the sample required for this study by using population prevalence proportion of $86 \%$ which turned out to be $>130$ patients 9 . Non probability Consecutive sampling technique was applied to collect the sample size for this study. Patients with type 2 diabetes mellitus with age 40-70 years taking atorvastatin for at least three to twelve months presenting to medical OPD were included in the study. Patients with history of rhabdomyolysis, taking concomitant fibrates or CP450 inhibitors or with history of major trauma or hypothyroidism were excluded from the study. Patient was defined having diabetes if by laboratory test show. A fasting plasma glucose concentration $>126 \mathrm{mg} / \mathrm{dl}$ (>7.0 mmol/l) at two different occasions (one week apart). Myopathy referred to muscle symptoms associated with elevations in $\mathrm{CK}$ at least 10 times the upper limit of normal and normal CK levels considered were 25-195 IU/L. Levels >10 times the upper limit of normal was considered having myopathy.

Patients with type 2 diabetes mellitus taking atorvastatin presenting to the medical outpatient department of Pak Emirates Military Hospital Rawalpindi fulfilling inclusion criteria were invited to participate in the study after getting approval from hospital ethics committee. Informed consent of willing patients was taken. Characteristics of patients including age, gender, weight, height, body mass index, duration of atorvastatin usage were recorded on a standardized data collection form. Blood samples were drawn and CK levels were determined by automated analysis by colorimetry. The results were verified by a pathologist.
Myopathy was noted as per operational definition by researcher himself.

Data was analyzed with statistical analysis program (SPSS-22). Mean \pm SD was presented for quantitative variables like age, duration of diabetes, duration of taking atorvastatin and CK levels. Frequency and percentage was computed for qualitative variables like gender and Myopathy. Stratification was done with regard to age, gender, duration of diabetes, duration of taking atorvastatin to see their effect on Myopathy. Post stratification chi square test was applied, $p \leq 0.05$ was considered statistically significant.

\section{RESULTS}

A total of 166 patients were included in the study. Mean age of patients was $51.530 \pm 5.70$ years with range between $40-70$ years. Mean duration of diabetes was $6.174 \pm 2.27$ years, mean duration of taking atorvastatin $7.186 \pm 2.17$ months and mean CK levels were $1760.325 \pm 5111.71 \mathrm{IU} / \mathrm{L}$ as shown in table-I. Males were $114(68.7 \%)$ as compare to females 52 (31.3\%). Myopathy was seen in $14(8.4 \%)$ patients. Stratification of Myopathy with respect to age, gender, duration of diabetes and duration of taking atorvastatin are shown in table-II. Long duration of DM and atorvastatin had statistically significant relationship with presence of myopathy among the target population ( $p$-value $<0.05)$.

Table-I: Descriptive summary table $(n=166)$.

\begin{tabular}{l|c}
\hline Demographics & Mean \pm SD \\
\hline Age (years) & $51.530 \pm 5.70$ \\
\hline $\begin{array}{l}\text { Duration of diabetes mellitus } \\
\text { (years) }\end{array}$ & $6.174 \pm 2.27$ \\
\hline $\begin{array}{l}\text { Duration of taking atorvastatin } \\
\text { (months) }\end{array}$ & $7.186 \pm 2.17$ \\
\hline CK levels (IU/L) & $1760.325 \pm 5111.71$ \\
\hline
\end{tabular}

Table-II: Relationship of myopathy with respect to different variables.

\begin{tabular}{|c|c|c|c|}
\hline \multirow{2}{*}{ Age (years) } & \multicolumn{2}{|c|}{ Myopathy } & \multirow[t]{2}{*}{$p$-value } \\
\hline & Yes & No & \\
\hline $40-55$ & $10(8.2 \%)$ & $112(91.8 \%)$ & \multirow{2}{*}{0.855} \\
\hline $56-70$ & $4(9.1 \%)$ & $40(90.9 \%)$ & \\
\hline \multicolumn{4}{|l|}{ Gender } \\
\hline Male & $10(8.8 \%)$ & $104(91.2 \%)$ & \multirow{2}{*}{0.816} \\
\hline Female & $4(7.7 \%)$ & $48(92.3 \%)$ & \\
\hline \multicolumn{4}{|c|}{ Duration of Taking Atorvastatin (months) } \\
\hline $3-6$ & $0(0 \%)$ & $66(100 \%)$ & \multirow{2}{*}{$<0.001$} \\
\hline $7-12$ & $14(14 \%)$ & $86(86 \%)$ & \\
\hline \multicolumn{4}{|c|}{ Duration of Diabetes (years) } \\
\hline $1-5$ & $2(2.6 \%)$ & $75(97.4 \%)$ & \multirow{2}{*}{0.012} \\
\hline$>5$ & $12(13.5 \%)$ & $77(86.5 \%)$ & \\
\hline
\end{tabular}




\section{DISCUSSION}

The principal finding of the present study was that $14(8.4 \%)$ of atorvastatin-treated patients had myopathy and frequency of myopathy increased with increase in duration of taking atorvastatin. The most common complaint was pain which was reported by 113 (93\%) of patients with myopathy. Pain was equally distributed between upper and lower extremities. Two patients complained of cramps in the lower limbs, and another two patients complained of weakness in the upper limbs. None of the patients complained of stiffness. The shortest interval between beginning the atorvastatin treatment and onset of symptoms was 7 days with a median period of 90 days.

The frequency of myopathy in atorvastatin users in our study slightly differ from what has been reported earlier ${ }^{10,11}$. The previous large, observational study -the PRIMO, reported $14.9 \%$ incidence of myopathy among patients taking high-dose atorvastatin $(40 \mathrm{mg}$ and $80 \mathrm{mg}$ per day). This slight difference may be explained by the fact that none of the patients in our study was taking $80 \mathrm{mg}$ per day of atorvastatin. We also observed lower frequency of muscle weakness 15 (14\%) compared to findings of PRIMO study (25\%). However, we cannot comment on these differences with certainty as we had small number of patients with myopathy and a large sample size could have better characterized the muscle symptoms.

In the present study, mean age of patients with myopathy and without myopathy was comparable. This finding suggested that myopathy in statin users were independent phenomena and is not influenced by age. This notion was further supported by earlier study findings conducted by Diamond et al in 201910 . However, Salman et al in 2019 in literature reported in contrast to our findings and have shown higher incidence $(>42 \%)$ of musculoskeletal symptoms in older age group ${ }^{12}$. Some of the researchers like Cooper et al in 2008 have attributed this reported higher incidence of musculoskeletal symptoms to a higher incidence of degenerative disease in older age group ${ }^{13}$. However, as reported by the PRIMO study physically active patients are more likely to develop myopathy, and older age group patients are less physically active and have a sedentary lifestyle leading to a decreasing incidence of myopathy in this age group.

The results of our study were in contrast to one observational study in literature that has reported much higher prevalence of myopathy among statin users. Cooper et al have reported a high incidence
$(65 \%)$ of muscles symptoms among statin users ${ }^{14}$. These patients belonged to a high age group (mean age $64.7 \pm 12.1$ years) who were likely to have frequent nonspecific musculoskeletal symptoms. A recent analysis on this subject by Armitage published in 2007 comparing the effect of dose on myopathy concluded that Atorvastatin $1 \mathrm{mg}$ and $2 \mathrm{mg}$ were equally responsible for causing the myalgias among the patients ${ }^{15}$. however, Gujral et al have reported no significant difference in myalgia among patients on low to moderate dose statin $(71 \%)$ compared to high dose statin (61\%), the effect of dose might have been nullified by higher mean age and longer duration of therapy in patients taking low to moderate dose of statin ${ }^{14}$. The frequency of myopathy observed in our study also contrasted with very low frequency of this adverse effect being described in various randomized controlled trials. Mergenhagen et al in 2014 have reported low incidence of myalgia that is $1-5 \%$ of patients in both the statin and placebo groups ${ }^{16}$.

This finding was similar to an earlier study conducted by Eisen et al who reported muscle-related symptoms in $39 \%$ patients but did not find any significant difference in Vitamin D level among patients with or without myalgia ${ }^{17}$. In a retrospective review done by Margenhagen et al they have reported lower incidence of adverse muscle events in the pati-ents treated with high-dose simvastatin $(80 \mathrm{mg})$ who also had a higher Vitamin D level. They suggested that correction of 25-hydroxyvitamin D levels before statin therapy initiation may mitigate one risk factor in the development of statin-related myalgia ${ }^{17}$.

There are several mechanisms postulated for statin-induced myopathy. Statin decreases cholesterol content of cell membrane so decreases its stability ${ }^{18}$. It has been also hypothesized that it reduces the production of ubiquinone (coenzyme Q10), which is a component of respiratory chain in inner mitochondrial membrane ${ }^{19}$. This deficiency lead to abnormal energy metabolism and thus muscle weakness ${ }^{20}$. Statins also prevent the formation of penylated proteins which include Ras, Rac, and Rho GTP-binding proteins.

There is not a single conscience for the management for statin-induced myopathy. All guideline recommend determining serum CK levels on the onset of myopathy only not in asymptomatic patients. For a symptomatic rise in serum CK levels $>10$ times the upper limit of normal, immediate discontinuation of drug is recommended ${ }^{20}$. If CK levels are in between 3 and 10 times the normal levels, there are different opi- 
nions among different guidelines stating suspension of statins till there is an improvement in symptoms.

\section{CONCLUSION}

Myopathy was found in a significant number of patients taking atorvastatin. High risk population in our study emerged out to be patients with long duration of DM and long use of atorvastatin.

\section{CONFLICT OF INTEREST}

This study has no conflict of interest to be declared by any author.

\section{REFERENCES}

1. Toth PP, Patti AM, Giglio RV, Nikolic D, Castellino G, Rizzo M, et al. Management of Statin Intolerance in 2018: Still More Questions Than Answers. Am J Cardiovasc Drugs 2018; 18(3): 157-73.

2. Hope HF, Binkley GM, Fenton S, Kitas GD, Verstappen SMM, Symmons DPM. Systematic review of the predictors of statin adherence for the primary prevention of cardiovascular disease. PLoS One 2019; 14(1): 1-38.

3. Chen ST, Huang ST, Shau WY, Lai CL, Li JZ, Fung S, et al. Longterm statin adherence in patients after hospital discharge for new onset of atherosclerotic cardiovascular disease: a population-based study of real world prescriptions in Taiwan. BMC Cardio-vasc Disord. 2019; 19(1): 62-66.

4. Thompson PD, Panza G, Zaleski A, Taylor B. Statin-associated side effects. J Am Coll Cardiol 2016; 67(20): 2395-410.

5. Stroes ES, Thompson PD, Corsini A. Statin-associated muscle symptoms: impact on statin therapy-European atherosclerosis society consensus panel statement on assessment, aetiology and management. Eur Heart J 2015; 36(17): 1012-22.

6. Stulc T, Ceška R, Gotto AM. Statin Intolerance: the Clinician's Perspective. Curr Atheroscler Rep 2015; 17(12): 69-72.

7. Rosenson RS, Baker SK, Jacobson TA. An assessment by the statin muscle safety task force: 2014 update. J Clin Lipidol 2014; 8(3): S58-71.

8. Panza GA, Taylor BA, Dada MR. Changes in muscle strength in individuals with statininduced myopathy: a summary of 3 investigations. J Clin Lipidol 2015; 9(3): 351-56.

9. Manoj K, Jain N. Myopathy in patients taking atorvastatin: a pilot study. Indian J Endocrinol Metab 2017; 21(4): 504-09.
10. Diamond DM, de Lorgeril M, Kendrick M, Ravnskov U, Rosch PJ. Formal comment on Systematic review of the predictors of statin adherence for the primary prevention of cardiovascular disease. PLoS One 2019; 14(1): 1-8.

11. Pedersen TR, Faergeman O, Kastelein JJ, Olsson AG, Tikkanen MJ, Holme I, et al. High-dose atorvastatin vs. usual-dose simvastatin for secondary prevention after myocardial infarction: The IDEAL study: A randomized controlled trial. J Am Med Assoc 2005; 294 (19): 2437-45.

12. Roghani RS, Delbari A, Asadi-Lari M, Rashedi V, Lökk J. Neuropathic Pain Prevalence of older adults in an urban area of Iran: A Population-Based Study. Pain Res Treat 2019; 2019: 9015695.

13. Cooper A, O'Flynn N. Guideline development group. risk assessment and lipid modification for primary and secondary prevention of cardiovascular disease: summary of NICE guidance. Bio Med J 2008; 336(5): 1246-48.

14. LaRosa JC, Grundy SM, Waters DD, Shear C, Barter P, Fruchart JC. Intensive lipid lowering with atorvastatin in patients with stable coronary disease. N Engl J Med 2005; 352(14): 1425-35.

15. Armitage J. The safety of statins in clinical practice. Lancet 2007; 370 (9601): 1781-90.

16. Mergenhagen K, Ott M, Heckman K, Rubin LM, Kellick K. Low vitamin $\mathrm{D}$ as a risk factor for the development of myalgia in patients taking high-dose simvastatin: a retrospective review. Clin Ther 2014; 36(5): 770-77.

17. Vilimanovich U, Bosnjak M, Bogdanovic A, Markovic I, Isakovic A, Kravic-Stevovic T, et al. Statin-mediated inhibition of cholesterol synthesis induces cytoprotective autophagy in human leukemic cells. Eur J Pharmacol 2015; 765(10): 415-28.

18. Ghirlanda G, Oradei A, Manto A, Lippa S, Uccioli L, Caputo S, et al. Evidence of plasma CoQ10-lowering effect by HMG-CoA reductase inhibitors: A double-blind, placebo-controlled study. J Clin Pharmacol 1993; 33(3): 226-29.

19. Laaksonen R, Jokelainen K, Laakso J, Sahi T, Harkonen M, Tikkanen MJ, et al. The effect of simvastatin treatment on natural antioxidants in low-density lipoproteins and high-energy phosphates and ubiquinone in skeletal muscle. Am J Cardiol 1996; 77(10): 851-54.

20. Pasternak RC, Smith SC, Bairey-Merz CN, Grundy SM, Cleeman JI, Lenfant C. American College of Cardiology; American Heart Association; National Heart, et al. ACC/AHA/NHLBI clinical advisory on the use and safety of statins. J Am Coll Cardiol 2003; 41(3): 510-20. 